\title{
A PRÁTICA DOS EXERGAMES NO CONTEXTO DA SAÚDE MENTAL: cartografando processos de acoplamentos
}

Adilson Rocha Ferreira Deise Juliana Francisco

\section{Resumo}

Esse estudo teve por objetivo verificar como se dá o acoplamento sujeito-máquina na interação de pessoas em sofrimento psíquico com os exergames. Para tal, a pesquisa foi norteada pelo método qualitativo, com a abordagem da pesquisa-intervenção. Foram realizadas oficinas com a participação de usuários de um CAPS de Maceió. Para registro dos dados produzidos foram utilizados a observação participante, a filmagem e o registro em diário de campo, analisados ao modo cartográfico. Ficou constatado que a organização estrutural do jogador se modificava ao passo que novas perturbações fossem sendo implementadas com novos jogos, desencadeando novos acoplamentos. Assim, surgiram novas modulações do acoplamento dos jogadores com os exergames, de modo a atender às novas demandas geradas. Ademais, os efeitos desencadeados guiavam o olhar para a descoberta de outras possibilidades de interação. Dessa forma, consideramos as oficinas de exergames como práticas de expressão corporal com potencialidades ao cuidado no âmbito da saúde mental.

Palavras-chave: sofrimento psíquico; videogames; educação; exercício físico; acoplamento.

\section{THE PRACTICE OF EXERGAMES IN THE MENTAL HEALTH} CONTEXT:

\author{
mapping coupling processes
}

\begin{abstract}
This study aimed to verify how the subject-machine coupling occurs in the interaction of people in psychological distress with exergames. For this, the research was guided by the qualitative method, with the research-intervention approach. Workshops were held with the participation of users of a CAPS in Maceió. To record the data produced, participant observation, filming and recording in a field diary were used, analyzed in the cartographic mode. It was found that the structural organization of the player changed as new disturbances were being implemented with new games, triggering new couplings. Thus, new modulations arose in the players' coupling with exergames, in order to meet the new demands generated. In addition, the triggered effects guided the look towards the discovery of other possibilities of interaction. Thus, we consider the exergame workshops as body expression practices with potential for care in the context of mental health.
\end{abstract}

Keywords: psychic suffering; video games; education; physical exercise; coupling. 


\section{LA PRÁCTICA DE EXERGAMES EN EL CONTEXTO DE SALUD}

MENTAL:

mapeo de procesos de acoplamiento

Resumen

Este estudio tuvo como objetivo verificar cómo se produce el acoplamiento sujeto-máquina en la interacción de las personas con problemas psicológicos con los juegos de ejercicios. Para ello, la investigación se guió por el método cualitativo, con el enfoque de investigación-intervención. Se realizaron talleres con la participación de usuarios de un CAPS en Maceió. Para registrar los datos producidos, se utilizó observación participante, filmación y grabación en un diario de campo, analizados en modo cartográfico. Se descubrió que la organización estructural del jugador cambió a medida que se implementaban nuevas perturbaciones con nuevos juegos, desencadenando nuevos acoplamientos. Por lo tanto, surgieron nuevas modulaciones en el acoplamiento de los jugadores con los juegos de ejercicios, para satisfacer las nuevas demandas generadas. Además, los efectos desencadenados guiaron la mirada hacia el descubrimiento de otras posibilidades de interacción. Por lo tanto, consideramos los talleres de ejercicios como prácticas de expresión corporal con potencial de atención en el contexto de la salud mental.

Palabras clave: sufrimiento psíquico; videojuegos; educación; ejercicio físico; acoplamiento.

\section{INTRODUÇÃO}

De acordo com Amarante (2007), historicamente o contexto da saúde mental é marcado por mobilizações que propõem a reestruturação do modelo assistencial às pessoas em sofrimento psíquico, na tentativa de extinguir os hospitais psiquiátricos - de onde surgiram denúncias de más condições e maus tratos - e estabelecer dispositivos humanizados para realização do cuidado. Com o intuito de assegurar os direitos das pessoas em sofrimento psíquico, o movimento da reforma psiquiátrica deu início às discussões acerca de um modelo assistencial humanizado, até que foi aprovada a Lei Federal n. 10.216, de 6 de abril de 2001, que dispõe sobre a proteção dos direitos das pessoas em sofrimento psíquico, bem como a reestruturação do modelo assistencial em saúde mental, a desinstitucionalização e a humanização (BRASIL, 2001).

Uma vez tendo a orientação da extinção progressiva dos hospitais psiquiátricos, com a Portaria da Secretaria Nacional de Assistência Social (SNAS) n. 224, de 29 de janeiro de 1992 são criados os Centros de Atenção Psicossocial (CAPS), que constituem a principal estratégia nesse novo modelo de assistência à pessoa em sofrimento psíquico (BRASIL, 1994). Os CAPS atuam com o objetivo de reinserir tais cidadãos na sociedade, promovendo a saúde e o bem-estar através de ações articuladas em forma de rede em conjunto com a família. Nesse novo modelo, com a Portaria GM n. 336, de 19 de fevereiro de 2002, as oficinas terapêuticas são criadas, constituindo a principal forma de tratamento oferecido no CAPS. São atividades desenvolvidas em grupo com a presença e orientação de profissionais, dentre os quais o professor de Educação Física. Este profissional passa a compor a equipe multidisciplinar, a fim de desenvolver oficinas terapêuticas que trabalhem com as habilidades corporais, sendo elas de expressão corporal, recreativas, esportivas, dentre outras (BRASIL, 2002; 2004). Entretanto, com a Nota Técnica n. 11/2019 do Ministério da Saúde (BRASIL, 2019), percebe-se que as mudanças propostas tentam destruir os princípios e estratégias de atenção psicossocial, conquistados pelas lutas da Reforma Psiquiátrica, o que pode representar um real retrocessos nas políticas de saúde mental no Brasil (GULJOR et al., 2019).

Um dos fenômenos que integram a cultura corporal do movimento e está presente na prática do professor de Educação Física é o fenômeno do jogo, sendo considerado como uma das 
práticas mais antigas do mundo, utilizada para definir como as civilizações antigas enfrentariam a escassez de alimentos (HERÓDOTO, 2015) e constituinte da cultura humana (HUIZINGA, 2014). No âmbito da saúde mental, parece relevante considerar que, a partir do jogo, busca-se a possibilidade de transformação da realidade em que o jogador se encontra, fugindo da confusão da vida e da imperfeição do mundo para uma perfeição temporária e limitada, levando-o a uma reflexão sobre a prática do jogo (HUIZINGA, 2014).

Para Gee (2010), as tecnologias digitais originam determinados efeitos - muito diferentes uns dos outros - em função dos contextos específicos em que se inserem. Nesse sentido, as tecnologias digitais podem se constituir em ferramentas potenciais para realização do cuidado no campo da saúde mental, pois quando implementadas em oficinas terapêuticas, proporcionam outros modos de fazer o cuidado, além de criar diferentes experiências de vida para pessoas em sofrimento psíquico devido à capacidade de convergência das mídias quando inseridas em atividades em grupo (FRANCISCO; AXT; MARASCHIN, 2007).

No contexto da era digital, o fenômeno do jogo também se apresenta inserido na era dos bits. $\mathrm{Na}$ perspectiva do jogo enquanto prática da cultura corporal do movimento, os exergames classe de jogos digitais que utiliza os movimentos do corpo humano para controlar as ações, feito esse antes só possível com controles manuais - tomam destaque devido às suas potencialidades de convergência. Essa classe de games teve uma maior popularização a partir da sétima geração de games, com a aparição dos consoles caseiros Playstation 3 (Sony Computer Entertainment), Nintendo Wii (Nintendo) e Kinect para Xbox 360 (Microsoft), proporcionando uma melhor experiência de imersão, além de aumentar o nível de atividade física do jogador (OH; YANG, 2010) e contrapor a visão dos malefícios dos videogames (SOTHERN, 2004; PAPASTERGIOU, 2009).

Nesse panorama, a presente pesquisa teve por objetivo verificar como se dá o acoplamento sujeito-máquina na interação pessoas em sofrimento psíquico com os exergames.

\section{ACOPLAMENTO ESTRUTURAL E TECNOLOGIAS DIGITAIS: VIVÊNCIAS}

Para Maturana e Varela (2001), os seres se constituem como unidades definidas pela sua organização autopoiética ${ }^{1}$, sendo essa organização constituída em sua rede de interações. A seguir, veremos como nascem os seres na interação de suas unidades com o meio: a ideia de acoplamento estrutural.

Para entendermos o conceito de acoplamento estrutural proposto por Maturana e Varela (2001) precisamos, antes, compreender o conceito dado à ontogenia. Para os autores, a ontogenia compreende o histórico de mudanças de uma unidade sem que esta perca a sua organização. Essas mudanças estruturais, que ocorrem de forma contínua, são desencadeadas pela interação da unidade com o meio em que é posta ou pela sua própria dinâmica interna. Assim, o resultado dessas interações será um histórico de mudanças estruturais até que unidade e meio se desintegrem, havendo, assim, o acoplamento estrutural.

De acordo com Maturana e Varela (2001), partimos do pressuposto que a ontogenia é a história de mudanças de um dado ser vivo. Assim, esse ser vivo tem sua estrutura inicial e surge em um dado meio, onde, ambos, têm uma estrutura dinâmica própria, a qual delimitará as modificações estruturais que serão desencadeadas. O ser vivo e o meio, mesmo possuindo

\footnotetext{
1 O conceito de autopoiese faz menção a um sistema capaz de produzir a si mesmo, tendo autonomia em seus níveis de operação, capaz de se autorreproduzir por meio de seus próprios elementos constitutivos (MATURANA; VARELA, 2001).
} 
estruturas distintas, possuem interdependência entre si, ocorrendo congruência estrutural necessária, pois, sem esta, não haveria unidade.

Nessa congruência estrutural estabelecida entre o ser vivo e o meio em que ele está, uma perturbação do meio no ser vivo não estabelece uma relação de causalidade específica sobre o ser vivo. Isto porque o ser vivo, por meio de sua estrutura própria, define quais modificações serão feitas em resposta à perturbação. Dessa forma, os autores salientam que:

Por isso, usamos a expressão desencadear um efeito, e com ela queremos dizer que as mudanças que resultam da interação entre o ser vivo e o meio são desencadeadas pelo agente perturbador e determinadas pela estrutura do sistema perturbado. O mesmo vale para o meio ambiente: o ser vivo é uma fonte de perturbações, e não de instruções (MATURANA, VARELA, 2001, p. 108).

Sendo assim, os agentes perturbadores, sejam eles provenientes do ser ou do meio, não são instrutivos, eles não determinam quais serão os efeitos. Quem define é a própria dinâmica da estrutura que recebe a perturbação.

Maturana e Varela (2001) distinguem quatro domínios de uma unidade estrutural específica. O primeiro deles é o domínio das mudanças do estado, que engloba as mudanças estruturais que uma unidade pode sofrer sem que se perca a sua identidade. Em seguida temos o domínio das mudanças destrutivas, que pelo próprio nome, refere-se às mudanças que resultam na perda da organização estrutural da unidade. O terceiro domínio é o das perturbações, o qual a partir de interações desencadeiam-se mudanças no estado da unidade. Por fim, há o domínio das interações destrutivas que reúne as perturbações que resultam na destruição da unidade.

Esses domínios são interpretados de acordo com o ser vivo e o seu pano de fundo em questão. Um choque entre uma moto e um poste pode ser visto como uma interação destrutiva das unidades, mas pode ser considerado apenas como uma perturbação quando há um tanque no lugar da moto no mesmo cenário interativo. Já que a organização estrutural de um sistema dinâmico está em constante mutação, seus domínios estruturais também serão afetados, constituindo um traço próprio da ontogenia de cada unidade dinâmica (MATURANA, VARELA, 2001).

De acordo com o que postulam os autores, podemos considerar que:

Enquanto uma unidade não entrar numa interação destrutiva com seu meio, nós, observadores, necessariamente veremos entre a estrutura do meio e a da unidade há uma compatibilidade ou comensurabilidade. Enquanto existir essa comensurabilidade, meio e unidade atuarão como fontes de perturbações mútuas e desencadearão mutuamente mudanças de estado. A esse processo continuado, demos o nome de acoplamento estrutural (MATURANA, VARELA, 2001, p. 112).

O acoplamento estrutural é justamente essa forma de interação entre a unidade e o meio, gerando fenômenos e acontecimentos que são recorrentes e repetitivos, sendo estes imprescindíveis à manutenção do sistema. Muito se tem investigado na relação dos humanos com as tecnologias e de que forma são entendidas essas modulações de acoplamento.

A ideia de acoplamento estrutural proposta por Maturana e Varela (2001) tem sido amplamente utilizada para embasar trabalhos que tem como propósito investigar as relações que o homem estabelece com as máquinas. Abaixo, traremos alguns desses trabalhos, com vistas a verificar como se operacionaliza o conceito de acoplamento estrutural com as experiências em oficinas com artefatos tecnológicos.

Carneiro (2003) analisou as possibilidades de constituição de novos domínios de aprendizagem, com ênfase nos processos comunicacionais que se estabelecem nos ambientes de 
aprendizagem envolvendo tecnologias, através dos acoplamentos tecnológicos que podem surgir a partir da interação de professores com diferenciados recursos tecnológicos. Para a autora, os mapas de interações gerados no estudo mostraram que a comunicação pode ser vista como um processo constituído na interação e nos acoplamentos tecnológicos e sociais que se estabeleceram.

No projeto de extensão Criando laços via recursos informatizados realizado a partir da parceria entre a Universidade Regional Integrada do Alto Uruguai e das Missões (URI), Campus Santo Ângelo e o Centro de Atenção Psicossocial da cidade de Santo Ângelo / Rio Grande do Sul (RS), Francisco (2007) realizou oficinas de informática com usuários do CAPS e cartografou as relações humano-máquina e as redes de convivência estabelecidas no uso dos recursos tecnológicos. Como parte dos resultados, a autora constatou que o acoplamento com as tecnologias digitais se tornou como um vetor que possibilitou a constituição de um comum, no sentido do desdobramento da experiência como constituinte da própria obra.

Em uma análise sobre como um grupo de professoras em condições perceptivas distintas escreve quando em contato com as mídias digitais, Demoly (2008), acompanhou as modalidades de escrita que as professoras - ouvintes e videntes no encontro com uma professora cega e outra professora surda - realizaram ao produzir um documento digital coletivamente. Em seus achados, a autora observou que atos de escrita coletiva e digital podem produzir uma convergência interativa que oferta uma gama de possibilidades de interlocução entre pessoas com capacidades perceptivas diferentes, pois as capacidades sensório-motoras são modificadas com o acoplamento com a escrita no meio digital.

Com o foco em aprofundar os modos de pesquisar e intervir através da fotografia no campo da saúde mental, Maurente (2010) desenvolveu um projeto com oficinas de fotografia para trabalhadores e usuários do Centro Integrado de Atenção Psicossocial do Hospital Psiquiátrico São Pedro em Porto Alegre / RS. Para a autora, as potencialidades das mídias digitais não surgem de forma imediata com a simples manipulação dos artefatos tecnológicos. Para que elas tomem corpo, é necessário que haja a formulação de intervenções que devem estar em consonância com as questões levantadas na pesquisa e as peculiaridades do campo. Para tal, é preciso que, durante o decorrer do estudo, sejam construídas modulações de acoplamentos tecnológicos.

Kroeff (2016) desenvolveu ao longo de 3 meses encontros no formato de oficina com o jogo baseado em localização chamado "Um Dia no Jardim Botânico", desenvolvido pelo Núcleo de Ecologias e Políticas de Cognição (NUCOGS) da Universidade Federal do Rio Grande do Sul (UFRGS). Participaram do estudo 33 estudantes com idade entre 11 e 15 anos e 5 professoras de uma escola de ensino fundamental do município de Porto Alegre / RS. Segundo a autora, foi possível identificar que para que haja o acoplamento, é essencial um saber-fazer que emerge da convivência e constitui a possibilidade de uma performance compartilhada a partir da relação humano-máquina.

A partir desse levantamento de pesquisas que utilizaram a ideia de acoplamento estrutural de Maturana e Varela (2001), percebemos que, na experiência inventiva, o acoplamento surge no âmbito coletivo, potencializado pelos encontros em forma de oficina. Assim, no momento em que homem e máquina interagem, ambos os domínios são afetados pelas perturbações que desencadeiam na congruência de suas unidades, gerando, assim, modificações estruturais de forma contínua enquanto houver interação.

\section{PERCURSO METODOLÓGICO}

A presente pesquisa é considerada de natureza qualitativa, pois demanda uma metodologia que analise questões subjetivas, levando em consideração as histórias de vida e os processos de 
construção envolvidos durante as vivência, pois, de acordo com Minayo (2010, p. 57) “[...] se aplica ao estudo da história, das relações, das representações, das crenças, das percepções e das opiniões, produtos das interpretações que os humanos fazem a respeito de como vivem, constroem seus artefatos e a si mesmos, sentem e pensam". Sendo assim, entende-se que a pesquisa qualitativa abrange a subjetividade, a realidade social, levando em consideração o posicionamento crítico do sujeito perante ao problema estudado.

Como abordagem metodológica, optamos por nos nortear pela perspectiva da pesquisaintervenção, a qual, segundo Paulon (2005) é marcada pelo potencial dos encontros, invenção e reinvenção, tendo como base a experimentação, que "[...] busca criar um campo de problematização, escavando outras dimensões do cotidiano e instaurando tensão entre representação e expressão, com a perspectiva de dar consistência a novos modos de subjetivação" (ROCHA, 2006, p. 171).

A presente pesquisa foi realizada em um CAPS situado na cidade de Maceió - AL com a participação de pessoas adultas em sofrimento psíquico usuárias deste CAPS, bem como os profissionais da instituição envolvidos com a pesquisa. No período do estudo, compunham a equipe do CAPS 1 médico, 1 enfermeiro, 1 nutricionista, 2 assistentes sociais, 1 psicólogo, 1 terapeuta ocupacional, 2 técnicas de enfermagem e 4 profissionais de apoio administrativo.

Durante o percurso das oficinas com os exergames no CAPS, muitos foram os usuários que participaram das oficinas, que aqui chamaremos de jogadores. Ao total, 16 jogadores passaram pelas oficinas, em que alguns começaram as atividades e evadiram, outros chegaram após o início, mas também evadiram e outros quatro participaram do início ao fim, mantendo-se assíduos aos encontros. Devido a isso, centraremos as análises nos dados produzidos por estes dois jogadores ao longo do estudo. Eles se auto denominaram Guile e Mário, os quais são personagens do mundo dos games.

Por nove meses e com encontros semanais foram desenvolvidas oficinas terapêuticas com a implementação dos exergames. Ao final do estudo, foram realizados 21 encontros, desde a chegada à instituição até o desenvolvimento das oficinas propriamente ditas com os usuários do CAPS.

Levando em consideração estudos anteriores (LEUTWYLER et al., 2012; LEUTWYLER, HUBBARD, DOWLING, 2014), os encontros tiveram duração em cerca de 60 (sessenta) a 70 (setenta) minutos, com horário definido juntamente com a instituição. Durantes as oficinas terapêuticas, os participantes utilizaram os exergames, especificamente o Kinect ${ }^{\mathrm{TM}}$ para Xbox $360^{\circledR}$. Foram disponibilizados diferentes jogos a serem utilizados nas oficinas, todos de classificação livre (Kinect Adventures, Kinect Sports First and Second Seasons, Kinect Joy Ride, Dance Central, Kinect Star Wars). Os jogos foram escolhidos por serem de classificação livre e simularem atividades com diferentes graus de amplitude do movimento, desde aqueles que requerem apenas os movimentos dos membros superiores (boliche, por exemplo) até aqueles que utilizam os movimentos do corpo todo (dança). Entretanto, os participantes foram encorajados a utilizar diferentes jogos em cada encontro.

Tendo em vista as pretensões desta pesquisa, enquanto instrumentos para registro dos dados produzidos durante as oficinas, foram utilizados a observação participante, a filmagem das oficinas e o registro em diário de campo pelo oficineiro.

Para análise dos dados produzidos, buscou-se interpretar e compreender as características, estruturas ou modelos que estão por trás das formas de comunicação e interação, bem como os modos de operar dos jogadores nas oficinas, sejam eles de qualquer natureza por meio do modo cartográfico, o qual implica em acompanhar processos e estar imbricado com a produção de 
subjetividade no ambiente da pesquisa (ALVAREZ, PASSOS, 2012). Assim, foi feita a decupagem² das filmagens das oficinas, considerando os participantes e os objetivos da pesquisa, a fim de observar e distinguir movimentos processuais recorrentes de transformação dos jogadores durante as oficinas com os exergames.

O projeto foi submetido na Plataforma Brasil e aceito pelo Comitê de Ética em Pesquisa (CEP) da Universidade Federal de Alagoas (UFAL) - CAAE: 61185416.4.0000.5013 (Parecer n. 1.869.721).

\section{RESULTADOS E DISCUSSÃO}

Nesta seção, discutiremos o que aconteceu com as relações entre jogador e máquina, a partir da inserção dos exergames como forma potencializadora no processo de reabilitação destas pessoas em sofrimento psíquico.

$\mathrm{Na}$ primeira oficina com os jogadores, não utilizamos os exergames propriamente ditos. Foi proposto o jogo Twister - um jogo de plataforma em que são dispostos círculos coloridos no chão e uma roleta, a qual indica a cor do círculo e o membro (mão direita ou esquerda; pé esquerdo ou direito) a ser colocado na cor indicada. O objetivo principal do jogo é se manter o maior tempo possível sem cair, envolvendo, além da estratégia, as capacidades físicas do corpo humano.

Logo que viram que a atividade não seria com os exergames, alguns jogadores saíram do local, não sendo atraídos pelo Twister. Aos poucos, os jogadores foram entendendo a dinâmica do jogo e desenvolveram a atividade, uns com mais facilidade, outros nem tanto. Goku foi o que mais sentiu dificuldade, talvez pelo excesso de peso e pela ausência do hábito de praticar exercício físico. Entretanto, Henry mostrou um bom desempenho na atividade, muitas vezes com quatro apoios, sem cair. A atividade nos mostrou que os usuários tinham diferentes níveis de condição física, o que foi muito importante para podermos delinear as oficinas com os exergames para que todos os jogadores pudessem usufruir daqueles momentos.

$\mathrm{Na}$ semana seguinte, ao chegar no CAPS, a terapeuta ocupacional comentou que a oficina foi muito comentada durante a semana por tratar de práticas corporais - que eles não trabalhavam por falta de profissional habilitado - e que não era surpresa o fato de dois usuários do CAPS não participarem, pois o mesmo acontecia em outras atividades em que eles eram convidados a integrar.

Levando em consideração a característica das diversas possibilidades de movimentos com os exergames, e a dificuldade que cada um impõe, decidimos por introduzir os jogos de forma que a amplitude dos movimentos fosse aumentando gradativamente, visando com que os jogadores fossem se familiarizando com a máquina.

Antes mesmo da oficina, mostramos aos jogadores um vídeo promocional do jogo Kinect Sports First Season, que mostra a modalidade de jogos digitais que eles usariam nas oficinas. Todos ficaram surpresos e riram bastante devido ao fato de jogar sem o controle. Dois usuários fizeram comentários interessantes: "Bom né, faz exercício físico também" (Henry); "É bom pra emagrecer" (Goku). Assim, como aquela seria a primeira interação entre os jogadores com os exergames, iniciamos com jogos que requerem poucos movimentos dos membros superiores - boliche e boxe - mesmo ouvindo diversos pedidos para jogar futebol. Naquele momento pensamos que não seria bom atender aquele pedido, pois precisávamos nos adaptar gradualmente ao artefato tecnológico para melhor desenvolver os futuros jogos que exigem mais movimentos do corpo.

A atividade começa e logo os primeiros produtos das interações aparecem:

\footnotetext{
${ }^{2} \mathrm{Na}$ linguagem audiovisual, decupagem diz respeito ao processo de seleção de cenas em um roteiro como parte do planejamento de uma filmagem.
} 
Ao explicar e olhar no rosto de cada participante, deu para sentir que tudo ali era novidade para eles, como constatado na primeira oficina. Entusiasmo e surpresa me pareceram ser constantes naquele momento (Diário de Campo do Oficineiro, dia 23 de fevereiro de 2017).

A relação com o jogo era uma novidade para eles. Como constatado em conversa anterior, mesmo tendo a maioria se relacionado antes com algum tipo de jogo digital, nenhum deles relatou ter vivenciado alguma prática com os exergames. Os jogadores se movimentavam lentamente e com movimentos robotizados, pois mesmo vivenciando aquela experiência, eles ainda não tinham a noção de como interagir com os jogos.

Ao mesmo tempo em que as relações interpessoais eram trabalhadas, as relações entre jogadores e máquina também foram explicitadas pelos próprios jogadores:

Com relação à primeira experiência com os exergames, Goku salientou a questão da corporeidade: "Eu já joguei outros jogos com controle, mas esse aqui é diferente. É que nem tipo assim a pessoa joga e ao mesmo tempo mexe com o corpo, o que é bom pra saúde". Goku relatou que se sentiu mais confiante jogando o exergame do que jogos com joystick (Diário de Campo do Oficineiro, dia 23 de fevereiro de 2017).

Parece-nos interessante ressaltar a questão de como os jogadores se relacionaram com os artefatos envolvidos nos jogos, como se deu esse acoplamento homem-máquina.

Durante a oficina, os jogadores observavam quem estava jogando naquele momento e a partir das ações do jogador, davam dicas e opiniões sobre qual seria a melhor opção de movimento a ser utilizado. Acredito que por muitas vezes quem estava jogando se sentia um pouco "perdido" em meio a tantas informações advindas tanto dos jogos, através das imagens e dos sons, quanto dos demais jogadores. Todo esse volume de informações parecia mexer com o jogador, de forma que o seu processamento de informações era constantemente posto em novas situações em decorrência de tudo que acontecia ao seu redor. No boliche, além dos elementos dos jogos, ouvia-se a todo tempo: "mais para a direita", "mais para a esquerda", "presta atenção nas setinhas para mirar a bola", "vai, joga com força" (Diário de Campo do Oficineiro, dia 27 de abril de 2017).

Nesse "mar" de informações, o jogador ia estabelecendo e efetivando coordenações através dos seus gestos nos jogos, pelas informações contidas nos elementos dos jogos ou nas falas dos seus colegas, de modo que as relações entre humano e máquina fossem desencadeadas através das fontes de perturbações que agem no jogador em um processo contínuo de ação, resultado no acoplamento, mediante as adaptações às perturbações. Como decorrência dessas adaptações, a organização estrutural do jogador se modificava ao passo que novas perturbações fossem sendo implementadas, o que desencadearia novos acoplamentos (MATURANA, VARELA, 2001).

Mas com o passar dos encontros, outros aspectos pareciam se evidenciar, de modo que os processos estabelecidos nas oficinas foram se modificando e mostrando nuances antes não percebidas. Assim, na segunda oficina com os exergames, pode-se observar:

Outro aspecto percebido foi com relação à repetição do movimento quando houve êxito. Quando o jogador conseguia rebater a bola vinda do adversário, ele não tinha noção da direção em que a bola ia, apenas repetia o movimento anterior, por falta de atenção ou apenas por automação do movimento exitoso (Diário de Campo do Ofícineiro, dia 2 de março de 2017). 
Os movimentos ainda eram robotizados, mecanizados e automatizados, levando em consideração os resultados das tentativas de sucesso na interação com os jogos. O acoplamento ia se modulando à medida que os jogadores atuavam nas partidas e era perceptível que, mesmo paulatinamente, as dificuldades iam diminuindo através da criação de novos modos de operar ao longo da interação com os exergames.

O acoplamento se modificava no transcorrer das oficinas. Como dito anteriormente, os jogos foram implementados de acordo com sua dificuldade e com o aumento gradual da amplitude dos movimentos corporais. Tivemos oficinas com jogos de boliche, dardo, basquetebol, beisebol, golfe, boxe, futebol, esqui, tênis de mesa, vôlei de praia, corrida de carro e jogos de aventura. Diferentes modalidades com características distintas, jogos com movimentos corporais simples e outros complexos, o que requer aprendizagem a cada desafio que o jogo impõe.

A cada oficina era um desafio, novidades, um degrau a mais a cada nova situação, novas perturbações que mexiam com a organização estrutural do jogador. Assim, ações de consciência corporal e capacidade cognitiva eram trabalhadas a todo momento, desencadeando efeitos a partir da interação com diversas possibilidades com os exergames.

Os movimentos robotizados vão sendo deixados de lado ao passo em que a interação entre jogadores e exergames se consolida. Hoje ao jogarmos Basquetebol, percebemos que as ações estão mais naturais, de modo que os jogadores já começam a perceber a evolução no trato com o jogo. Em ambos os jogadores isso é visível, mas em Mário principalmente. Os braços cruzados já não são tão evidentes quanto antes. A comunicação entre os jogadores está mais fluída, trocam experiências e estratégias, ao passo que se divertem comentando os modos de jogar, as feições, os gestos, as emoções (Diário de Campo do Oficineiro, dia 01 de junho de 2017).

Nessas circunstâncias, Kroeff e Baum (2017) afirmam que:

Quando algum participante está jogando, ele simultaneamente interage com o mundo do jogo e experimenta a si mesmo habitando esse mundo. Experimentando o fluxo de informações que vem do videogame, seja o som ou as imagens, ao mesmo tempo se percebe imerso nele. A atenção circula entre o videogame e uma atenção a si. Ao mesmo tempo em que se concentra no processo de jogar, ele se percebe concentrado no processo de criação, de jogo. É como se houvesse dois lados da mesma experiência: o participante se percebe como parte de um processo e é capaz de se surpreender com algumas coisas que fala, com sua forma de agir ou com a ideia que deu e foi aceita e acabou vindo a compor aquela experiência do jogo (KROEFF, BAUM, 2017, p. 110).

A cada modalidade vivenciada, um novo conjunto de movimentos era requerido para atingir os objetivos dos desafios propostos. Do simples (movimentos dos membros de forma isolada) ao complexo (movimentos do corpo como um todo): essa foi a lógica utilizada para implementação dos jogos nas oficinas. Lançar a bola no boliche, golpear com socos no boxe, lançar a bola na cesta, chutar a bola no futebol, golpear a bola do tênis de mesa, controlar o volante dos carros. Diferentes movimentos em cada jogo, o que exige a aprendizagem do movimento em si através da experimentação proporcionada pela imersão dos jogos.

Sempre ao início das oficinas, decidíamos qual jogo utilizar naquele momento. Depois de algum tempo, algo me pareceu evidente: os jogadores queriam sempre jogar o que haviam jogado na semana anterior, recusando-se a conhecer outros jogos. Entretanto, eu fiz uma proposta a eles: iniciar a oficina jogando as modalidades vivenciadas na oficina anterior e no segundo momento introduzir 
um jogo que eles ainda não tinham jogado. Foi aí que começamos a agenciar as formas de construir as oficinas (Diário de Campo do Oficineiro, dia 23 de março de 2017).

Frente aos novos desafios, surgiam as incertezas, a insegurança, o medo de errar, de não conseguir alcançar o objetivo do jogo. A frustação do fracasso nas missões dos jogos é contornada pela possibilidade de uma nova chance de acertar. Entretanto, dentro da diversidade de jogos experimentados nas oficinas, um deles tomou destaque e por mais incrível que pareça para o oficineiro, não foi o futebol que eles tanto comentavam e pediam para jogar no início da pesquisa. A ação do conhecer faz parte vida cotidiana, e o conhecer não se dá apenas no seu ato, e sim através daquele que observa. Assim:

De modo que esta ação do conhecer, de como conhecemos, como se validam nossas coordenações cognitivas, não é de modo algum trivial. Ela pertence à vida cotidiana. Estamos imersos nisto momento a momento. Por isso somos nós, observadores, o ponto central e o ponto de partida da reflexão (MATURANA, 2014, p. 24-25).

A ideia de "reflexão" é diferente e oposta da noção de aquisição de informação. Levando em consideração a noção de autopoiese, sente-se a necessidade de uma reflexão devido ao fato de que:

A reflexão é um processo de conhecer como conhecemos, um ato de voltar a nós mesmos, a única oportunidade que temos de descobrir nossas cegueiras e reconhecer que as certezas e os conhecimentos dos outros são, respectivamente, tão nebulosos e tênues quanto os nossos (MATURANA, VARELA, 2001, p. 2930).

O boliche os cativou de uma forma surpreendente. Talvez pela simplicidade dos movimentos exigidos para jogar a modalidade ou uma complexidade relativa dos demais jogos fez com que as oficinas fossem direcionadas para tal prática. Entretanto, levando em conta o acoplamento, este continuou em contínuo desenvolvimento levando em consideração às regras impostas pelos próprios jogadores. Nas oficinas, eles convencionaram regras paralelas ao jogo do boliche como por exemplo jogar com a mão não-dominante. Assim, o jogador destro deveria executar a ação com a mão esquerda e o oposto ao jogador canhoto.

A pontuação de uma partida de boliche varia de acordo com a quantidade de pinos e a forma como o jogo os derruba, podendo ir de 0 (quando nenhum pino é derrubado nas dez jogadas) até 300 pontos (12 strikes consecutivos - quando se derruba todos os 10 pinos na primeira jogada). Devido às adaptações às perturbações provenientes dos desafios do jogo de boliche, os jogadores conseguiram se reorganizar estruturalmente de tal forma que os jogadores faziam muitos strikes em suas jogadas, fato este que era raro no início das intervenções. Assim, com o desenrolar das oficinas, o jogo foi ficando monótono, até o momento que Guile sugeriu:

O que acha se agora tentássemos derrubar apenas um pino ao invés de todos? Tipo, eu digo: "Mário, derrube o último pino da esquerda", daí ele tem que derrubar apenas o pino que eu mandei para fazer o ponto. Bora? (Diário de Campo do Oficineiro, dia 6 de julho de 2017)

Mesmo que de forma inconsciente, os jogadores estavam criando novas regras, de modo a produzir novas perturbações no meio que, por sua vez, produziria novas perturbações nos jogadores. Assim, de acordo com Maturana (2014, p. 194): 
$\mathrm{Na}$ medida em que o humano se iniciou com a conservação, geração após geração, do viver na linguagem como a característica relacional básica que definiu nossa linhagem, o que realmente começou foi a conservação transgeracional do viver em conversações. Nós, seres humanos vivemos em conversações, e tudo o que fazemos como tais, o fazemos em conversações como redes de entrelaçamento consensual de emoções e coordenações de coordenações de comportamentos consensuais.

O mundo em que vivemos surge a partir das nossas conversações. As oficinas foram sendo construídas a partir das conversações entre os jogadores, no compartilhamento de ideias, estratégias e frustrações, de modo a estabelecer outras formas de jogar, outras formas de interagir com os exergames, outras formas de operar mediante o novo, que foram sendo implementadas pelos próprios jogadores.

Assim, novos efeitos eram desencadeados: não se tratava mais de mirar nos pinos para derrubar todos na primeira jogada e, sim, controlar seu corpo, usar a lateralidade e os efeitos de movimento para que apenas determinados pinos fossem derrubados. Sendo assim, surgiram novas modulações do acoplamento dos jogadores com os exergames, de modo a assumir outras relações para atender as demandas agora postas por eles mesmos. No começo foi difícil, estavam adaptados ao boliche convencional. Entretanto, outras estratégias foram sendo postas à prova: os jogadores se deslocavam no espaço, colocando-se em posições diferentes daquelas que executavam com o membro dominante. Diante dessa troca de informações entre jogadores e máquinas, os efeitos desencadeados mostraram outras possibilidades de interação, até então desconhecidas.

\section{CONSIDERAÇÕES FINAIS}

Na perspectiva dos princípios da Reforma Psiquiátrica e da reformulação do modelo assistencial em saúde mental, com a adoção de práticas mais humanizadas, o presente estudo teve como problemática instigar a abertura de diálogo entre os exergames e o cuidado em saúde mental. Isto no intuito de criar outras possibilidades que possam potencializar o cuidado para pessoas em sofrimento psíquico em seus processos de reabilitação psicossocial. Sendo assim, esta pesquisa verificou como se dá o acoplamento sujeito-máquina na interação dos oficinandos com os exergames.

O referencial teórico que embasou a inferência e a reflexão na fase de análise de dados sobre os processos estabelecidos durante as oficinas com os exergames foi de suma importância. A teoria da Biologia do Conhecer de Maturana e Varela (2001) nos ajudou a explicar os processos cognitivos a partir da sua processualidade, encarando a aprendizagem como uma ação inventiva e o ser humano como inacabado, sempre em processo, sempre em ação.

Ao mesmo tempo em que as relações interpessoais eram trabalhadas, as relações entre jogadores e máquina também estavam em processo. A partir da interação com o grande volume de informações contido nos exergames, o jogador ia estabelecendo e efetivando coordenações através dos seus gestos nos jogos, de modo que as relações entre jogador e exergames fossem desencadeadas através das fontes de perturbações - nesse caso, os desafios dos jogos que agiram no jogador em um processo contínuo de ação, resultando no acoplamento, mediante adaptações às perturbações.

Como decorrência das adaptações, a organização estrutural do jogador se modificava, ao passo em que novas perturbações fossem sendo implementadas com novos jogos, desencadeando novos acoplamentos que foram modulados, à medida que os jogadores experimentavam diferentes jogos, criando novos modos de operar ao longo da interação com os exergames. 
O acoplamento estava sempre em processo. A cada oficina surgiam novos desafios, constituindo novas perturbações que mexiam com a organização estrutural do jogador. A cada jogo vivenciado, novos movimentos eram requeridos para atingir os objetivos dos desafios propostos. A partir dos novos movimentos, exigia-se aprendizagem na experimentação proporcionada pela imersão nos jogos.

Com a experimentação, novos efeitos eram desencadeados: não se tratava mais de seguir regras impostas pelos jogos mas, sim, criar coletivamente um novo conjunto de regras, modificando a dinâmica e criando perturbações. Sendo assim, surgiram novas modulações do acoplamento dos jogadores com os exergames, de modo a assumir outras relações para atender a novas demandas geradas pelas regras criadas. Diante dessa troca de informações entre jogadores e máquinas, os efeitos desencadeados guiavam o olhar para a descoberta de outras possibilidades de interação até então desconhecidas.

Nesse sentido, a presente pesquisa passa a contribuir no cenário de invenção de novas práticas de cuidado no âmbito da saúde mental, elencando outras práticas relacionadas com o cuidado, ao considerar a prática dos exergames como prática de expressão corporal, desenvolvida por meio de oficinas, com potenciais benefícios ao cuidado em saúde mental.

\section{REFERÊNCIAS}

ALVAREZ, Johnny; PASSOS, Eduardo. Cartografar é habitar um território existencial. In: PASSOS, Eduardo; KASTRUP, Virgínia; ESCÓSSIA, Liliana. Pistas do método da cartografia: pesquisa-intervenção e produção de subjetividade. Porto Alegre: Sulina, 2012. p. 132-150.

AMARANTE, Paulo. Saúde mental e atenção psicossocial. Rio de Janeiro: SciELO-Ed. FIOCRUZ, 2007.

BRASIL. Ministério da Saúde. Lei n. 10.216, de 6 de abril de 2001. Dispõe sobre a proteção e os direitos das pessoas portadoras de transtornos mentais e redireciona o modelo assistencial em saúde mental. Diário Oficial da União, 2001.

BRASIL. Ministério da Saúde. Nota técnica n. 11/2019-CGMAD/DAPES/SAS/MS. Brasília (DF), 4 fev. 2019. Assunto: Esclarecimentos sobre as mudanças na Política Nacional de Saúde Mental e nas Diretrizes da Política Nacional sobre Drogas. Disponível em http://pbpd.org.br/wpcontent/uploads/2019/02/0656ad6e.pdf. Acesso em 19 mar. 2020.

BRASIL. Ministério da Saúde. Portaria SNAS n. 224, de 29 de janeiro de 1992: estabelece diretrizes e normas para o atendimento em saúde mental. Diário Oficial da União, 1994.

BRASIL. Ministério da Saúde. Secretaria de Atenção à Saúde. Departamento de Ações Programáticas Estratégicas. Saúde mental no SUS: os Centros de Atenção Psicossocial. Brasília: Ministério da Saúde, 2004.

CARNEIRO, Mára Lúcia Fernandes. O acoplamento tecnológico e a comunicação em rede: inventando outros domínios de aprendizagem. 2003. 187 f. Tese (Doutorado em Informática na Educação) Programa de Pós-Graduação em Informática na Educação, Universidade Federal do Rio Grande do Sul, Porto Alegre, 2003.

DEMOLY, Karla Rosane do Amaral. Escritura na convergência de mídias. 2008. 213 f. Tese (Doutorado em Informática na Educação) - Programa de Pós-Graduação em Informática na Educação, Universidade Federal do Rio Grande do Sul, Porto Alegre, 2008. 
FRANCISCO, Deise Juliana. Criando laços via recursos informatizados. 2007. 172 f. Tese (Doutorado em Informática na Educação) - Programa de Pós-Graduação em Informática na Educação, Universidade Federal do Rio Grande do Sul, Porto Alegre, 2007.

FRANCISCO, Deise Juliana; AXT, Margarete; MARASCHIN, Cleci. Informática e saúde mental: caminhos de uma oficina. RENOTE: Revista Novas Tecnologias na Educação, Porto Alegre, v. 5, n. 1, p. 1-16, 2007. Disponível em http://seer.ufrgs.br/index.php/renote/article/view/14303. Acesso em 12 maio 2019.

GEE, James Paul. Bons videojogos + boa aprendizagem: colectânea de ensaios sobre os videojogos, a aprendizagem e a literacia. Portugal: Edições Pedágio, 2010.

GULJOR, Ana Paula Freitas et al. Nota de Avaliação Crítica da Nota Técnica 11/2019: "Esclarecimentos sobre as mudanças na Política Nacional de Saúde Mental e nas Diretrizes na Política Nacional sobre Drogas", emitida pela Coordenação Nacional de Saúde Mental, Álcool e Outras Drogas, do Ministério da Saúde, em 04/02/2019, de autoria de Quirino Cordeiro Junior. Disponível em http://www.crpri.org.br/site/wp-content/uploads/2019/02/Note-tecnica-SaudeMental.pdf. Acesso em 19 mar. 2020.

HERÓDOTO. Histórias - Livro I - Clio. São Paulo: Edipro, 2015.

HUIZINGA, Johan. Homo ludens: o jogo como elemento da cultura. 8. ed. São Paulo: Perspectiva, 2014.

KROEFF, Renata Fischer da Silveira. Experiências coletivas com tecnologias digitais: um encontro entre videogames e a cultura da mobilidade. 2016. 97 f. Dissertação (Mestrado em Psicologia Social e Institucional) - Programa de Pós-Graduação em Psicologia Social e Institucional, Universidade Federal do Rio Grande do Sul, Porto Alegre, 2016.

KROEFF, Renata; BAUM, Carlos. Oficinas e pesquisa-intervenção: videogames como processo enativo. In: MARASCHIN, Cleci; KROEFF, Renata; GAVILLON, Póti (orgs.). Oficinando com jogos digitais: experiências de aprendizagem inventiva. Curitiba: CRV, 2017.

LEUTWYLER, Heather et al. Videogames to Promote Physical Activity in Older Adults with Schizophrenia. Games for Health Journal, [s. 1.], v. 1, n. 5, p. 381-383, 2012. Disponível em http://online.liebertpub.com/doi/abs/10.1089/g4h.2012.0051. Acesso em 15 ago. 2019.

LEUTWYLER, Heather; HUBBARD, Erin M.; DOWLING, Glenna A. Adherence to a Videogame-Based Physical Activity Program for Older Adults with Schizophrenia. Games for Health Journal, [s. 1.], v. 3, n. 4, p. 227-233, 2014. Disponível em http://online.liebertpub.com/doi/abs/10.1089/g4h.2014.0006. Acesso em 15 ago. 2019.

MATURANA, Humberto R.; VARELA, Francisco J. $A$ árvore do conhecimento: as bases da compreensão humana. São Paulo: Palas Athena, 2001.

MATURANA, Humberto. Cognição, ciência e vida cotidiana. Belo Horizonte: Editora UFMG, 2014.

MAURENTE, Vanessa Soares. Imagens do hospicio vaz̧io: fotografia, pesquisa e intervenção. 2010. 215f. Tese (Doutorado em Informática na Educação) - Programa de Pós-Graduação em Informática na Educação, Universidade Federal do Rio Grande do Sul, Porto Alegre, 2010.

MINAYO, Maria Cecília de Souza (org.). O desafio do conbecimento: pesquisa qualitativa em saúde. São Paulo: Hucitec, 2010.

OH, Yoonsin; YANG, Stephen. Defining exergames and exergaming. Proceedings of Meaningful Play, p. $1-17,2010.2$ Disponível em http://meaningfulplay.msu.edu/proceedings2010/mp2010 paper 63.pdf. Acesso em 17 mar. 2019. 
PAPASTERGIOU, Marina. Exploring the potential of computer and video games for health and physical education: a literature review. Computers \& Education, v. 53, n. 3, p. 603-622, 2009. Disponível $\mathrm{em}$ https://www.sciencedirect.com/science/article/abs/pii/S0360131509000840?via\%3Dihub. Acesso em 6 ago. 2019.

PAULON, Simone Mainieri. A análise de implicação com ferramenta na pesquisa-intervenção. Psicol. Soc., Porto Alegre, v. 17, n. 3, p. 18-25, 2005. Disponível em http://www.scielo.br/scielo.php?pid=S0102-71822005000300003\&script=sci_abstract\&tlng=pt. Acesso em 12 fev. 2019.

ROCHA, Marisa Lopes da. Psicologia e as práticas institucionais: a pesquisa-intervenção em movimento. Psico, v. 37, n. 2, p. 169-174, 2006. Disponível em http://revistaseletronicas.pucrs.br/ojs/index.php/revistapsico/article/view/1431. Acesso em 25 out. 2019.

SOTHERN, Melinda S. Obesity prevention in children: physical activity and nutrition. Nutrition, v. 20, n. 7, p. 704-708, 2004. Disponível em https://www.nutritionjrnl.com/article/S08999007(04)00098-X/fulltext. Acesso em 8 jan. 2019.

\section{AGRADECIMENTOS}

Os autores gostariam de agradecer à Fundação de Amparo à Pesquisa do Estado de Alagoas (FAPEAL) pela concessão de Bolsa de Doutorado ao primeiro autor e à Coordenação de Aperfeiçoamento de Pessoal de Nível Superior (CAPES) pela Bolsa PNPD da segunda autora. Ainda, agradecemos à FAPEAL pelo financiamento da pesquisa através do Edital n. 13/2016 Apoio a Pesquisas - PPGs/Humanidades.

Submetido em marco de 2020 Aprovado em julho de 2020

\section{Informações do(a) autor(a)}

Adilson Rocha Ferreira

Mestre e Doutorando em Educação pela Universidade Federal de Alagoas (UFAL). Docente da Secretaria de Estado da Educação de Alagoas (SEDUC/AL)

E-mail:adilsonrf.al@gmail.com

ORCID: http://orcid.org/0000-0001-5858-5935

Link Lattes: http://lattes.cnpq.br/0303655687584004

Deise Juliana Francisco

Docente do Centro de Educação (CEDU) da Universidade Federal de Alagoas (UFAL)

E-mail:deisej@gmail.com

ORCID: http://orcid.org/0000-0003-2130-2588

Link Lattes: http://lattes.cnpq.br/3256764275787933 